\title{
A PRAÇA MORENA BELA NA CIDADE DE SERRINHA-BA: UMA REFLEXÃO A PARTIR DA PAISAGEM URBANA
}

\author{
The Morena Bela Square in the city of Serrinha-BA: a reflection from the urban \\ landscape
}

\section{La Plaza Morena Bella en la ciudad de Serrina-BA: una reflexión a partir del paisaje urbano}

\footnotetext{
${ }^{1}$ Especialista em Dinâmia Territorial e Socioambiental do Espaço Baiano - UEFS. Membro do Grupo de Pesquisa Geo(Bio)Grafar-UNEB Departamento de Educação Campus XI - Serrinha- Bahia-Brasil fernandodsouzanunes@hotmail.com
}

\section{Resumo}

A paisagem, o horizonte que nos é apresentado cuja visão consegue abarcar, faz parte do nosso cotidiano. Descrever a paisagem é insuficiente e faz-se necessário revelar as suas entrelinhas. Sendo a praça um espaço público, mais especificamente das praças, temos, pois, o In loco da ação coletiva, das inúmeras subjetividades, funcionalidades e seu papel no cenário urbano da cidade. Eis a Praça Morena Bela da cidade de Serrinha, objeto de estudo deste trabalho vista sob o olhar revelador da paisagem categoria de análise da Geografia. Este trabalho revisou a literatura acerca de paisagem e praça com a finalidade de estudar os processos sócioespaciais que resultaram na atual configuração da Praça Morena Bela, atualizando novas impressões e aprofundando uma leitura para além do que a visão pode apresentar. Dessa forma, pode-se inferir que sua paisagem é heterogênea em cores e sensações; dinâmica por ser composta de formas naturais e artificiais, imbricadas de inúmeras temporalidades e funções, resultante de inúmeros eventos e modificações por meio da técnica estando em constante modificação.

Palavras-chave: Espaço público. Paisagem. Praça.

\footnotetext{
Abstract

The landscape, the horizon that is presented to us whose vision can encompass, is part of our daily life. Describing the landscape is insufficient and it is necessary to reveal its lines. Being the square a public space, more specifically of the squares, we have, therefore, the In loco of the collective action, of the numerous subjectivities, functionalities and their role in the urban scenery of the city. This is the Morena Bela Square in the city of Serrinha, object of study of this work seen under the revealing look of the landscape - category of Geography analysis. This work reviewed the landscape and square literature in order to study the socio-spatial processes that resulted in the current configuration of
} 
Morena Bela Square, updating new impressions and deepening a reading beyond what the vision can present. In this way, it can be inferred that its landscape is heterogeneous in colors and sensations; dynamic because it is composed of natural and artificial forms, imbricated by innumerable temporalities and functions, resulting from innumerable events and modifications by means of the technique being constantly modified.

Keywords: Public space. Landscape. Square.

\section{Resumen}

El paisaje, el horizonte que nos es presentado cuya visión logra abarcar, forma parte de nuestro cotidiano. Describir el paisaje es insuficiente y es necesario revelar sus entrelíneas. Siendo la plaza un espacio público, más específicamente de las plazas, tenemos, pues, el In loco de la acción colectiva, de las innumerables subjetividades, funcionalidades y su papel en el escenario urbano de la ciudad. Es la Plaza Morena Bella de la ciudad de Serrinha, objeto de estudio de este trabajo vista bajo la mirada reveladora del paisaje - categoría de análisis de la Geografía. Este trabajo revisó la literatura acerca de paisaje y plaza con la finalidad de estudiar los procesos socioespaciales que resultaron en la actual configuración de la Plaza Morena Bela, actualizando nuevas impresiones y profundizando una lectura más allá de lo que la visión puede presentar. De esta forma, se puede inferir que su paisaje es heterogéneo en colores y sensaciones; dinámica por estar compuesta de formas naturales y artificiales, imbricadas de innumerables temporalidades y funciones, resultante de innumerables eventos y modificaciones por medio de la técnica estando en constante modificación.

Palabras clave: Espacio público. Paisaje. Plaza.

\section{Introdução}

$\mathrm{Na}$ trajetória cotidiana, constantemente nos deparamos com uma imagem que é capturada pela nossa visão podendo nos sensibilizar ou ser tratada como trivial e menos importante sob o olhar do senso comum.

Tudo que o ser humano consegue abarcar com o sentido da visão se converte em um horizonte: a vista que se tem um carro ou avião quando se olha para a janela movimento, da praia, dos locais turísticos e outros é uma paisagem. Porém, aprecia-la discplicentimente é insuficiente e faz-se necessário revelar as suas entrelinhas. Assim é a paisagem para os geógrafos que, por excelência estudam esta categoria de análise geográfica.

Neste trabalho, o objeto de estudo é a Praça Morena Bela da cidade de Serrinha, localizada no Território de Identidade do Sisal, Mesorregião Nordeste do Estado da Bahia, (Figura 1). 
Figura 1 - Mapa do município de Serrinha no contexto do Estado da Bahia - 2017

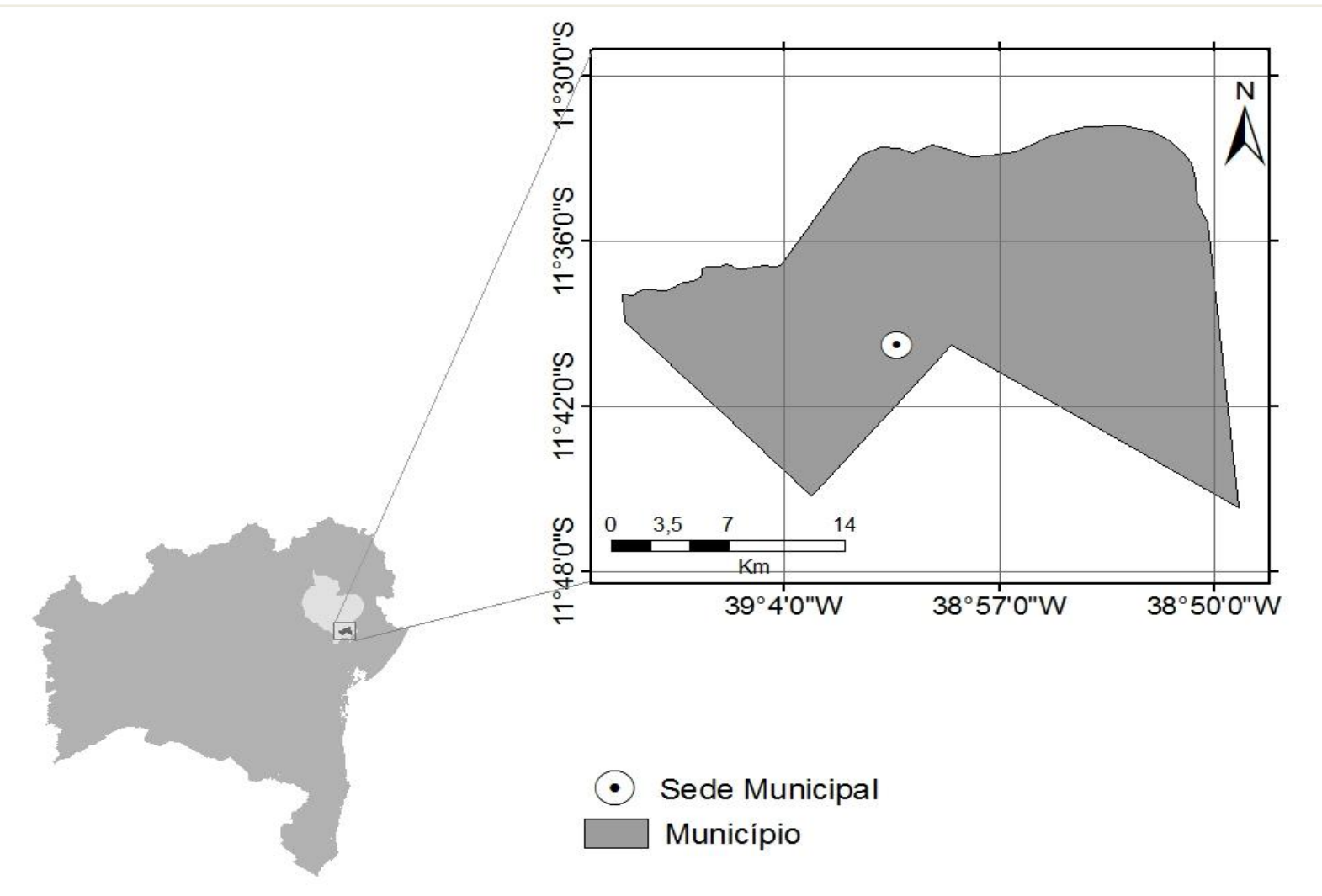

Fonte: elaborado pelo autor

Os objetivos desse artigo foram o de revisar a literatura acerca dos temas paisagem urbana e praça; compreender os processos espaciais responsáveis pelo surgimento da Praça Morena Bela.

A metodologia teve como base, num primeiro momento, algumas reflexões feitas na elaboração da Monografia, apontando as dinâmicas da Praça Morena Bela por meio de estudo da paisagem urbana desse espaço.

Além deste, discutiu-se os resultados obtidos por fontes primárias como as entrevistas aos agentes sociais da pesquisa como: estudantes (oriundo das escolas existente no entorno da praça), moradores (devido a relevância para a pesquisa), transeuntes (pertencem as diversas camadas sociais sem ligação direta com a praça em relação a outros agentes), servidores públicos (uma das categorias de maior frequência na pesquisa devido a presença de órgãos públicos no entorno da praça) e comerciantes (proprietário de bares, restaurantes e vendedores ambulantes). 
A maioria dos agentes é do sexo masculino em idade economicamente ativa, naturais do município de Serrinha, possuem nível superior incompleto e ganham acima de dois salários mínimos.

Estes mesmos agentes frequentam a praça há mais de dez anos e o tempo de uso e apropriação do referido espaço público ocorre diariamente, ou, em todos os dias da semana, conforme a necessidade e a função que exercem.

Num segundo momento, fez-se levantamento bibliográfico mediante consulta a artigos, monografias, dissertações e análises documentais que abordam os temas referentes às praças públicas e paisagem urbana.

\section{Paisagem}

A paisagem é uma das categorias de análise da Geografia sendo abordada por diversas ciências, tais como: Sociologia, Antropologia, Artes, entre outras e apresenta uma grande polissemia de conceitos e sentidos, todavia, neste trabalho, nos atemos ao seu significado para a ciência geográfica: (...) "a paisagem enquanto conceito expressa uma multiplicidade de maneiras de abordagem" (SCHIER 2003, p. 80).

Dessa forma, elegemos, para este artigo, a seguinte definição acerca do tema:

A paisagem é o conjunto de objetos que nosso corpo alcança e identifica. O jardim, a rua, o conjunto de casas que temos à nossa frente, como simples pedestres. Uma fração mais extensa de espaço, que a nossa vista alcança do alto de um edifício. (...) A paisagem é o nosso horizonte, estejamos onde estivermos (SANTOS, 2008, p. 84).

Quando se trata do conjunto de objetos, faz-se referência aos itens, ou elementos, que compõem a paisagem, seja ela os vegetais (plantas e árvores), os animais e as edificações (casarões antigos, prédios, dentre outros). Nisso constatamos que a principal definiçãa sobre paisagem perpassa por aquilo que a visão abarca.

Tais paisagens agem diretamente em nossos sentidos, em especial nas nossas memórias, atuando como um registro estacado e marcado em nosso imaginário. Por isso

$\mathrm{Na}$ ciência geografica, a paisagem é um conjunto de estruturas socioespaciais de um determinado local, que permite uma espécie de interatividades entre si e o homem, que a "percebe" por meio de seus sentidos, principalmente a visão. (...) É comum que as pessoas considerem como paisagem apenas uma soma de diversos elementos naturais, como montanha, rios e florestas, mas há as que são formadas pela intervenção humana, responsável pela criação de edificações, plantações, casas, pontes, ruas e afins (MACHADO, 2008 p. 54). 
Em qualquer lugar do planeta haverá a classificação da paisagem por meio dessas duas vertentes. Sua heterogeneidade de formas e estruturas, multiplicidade de funções e a diversidade de agentes refletem a complexidade deste tema, visto que, em linhas gerais, quanto mais a paisagem é alterada pelos humanos mais artificial ela se apresenta e, mesmo aquelas tidas como naturais, mas que escondem uma segunda natureza modificada pela cultura agrícola/exploratória ou pastoril, aproximando-se de uma certa artificialidade.

Vale salientar que o próprio autor em questão adverte que “[...] a paisagem não é dada para todo o sempre, é objeto de mudanças. É um resultado de adições sucessivas. É uma espécie de marcas da história do trabalho, das técnicas" (SANTOS, 2008, p. 74-75).

Aqui percebemos que espaço e tempo são intimamente indissociáveis e se complementam mutuamente, podemos observar que a paisagem é consequência da ação humana ao longo da história, por meio do uso da técnica, estando constantemente sujeita a modificações ao longo do seu decurso, visto que:

\begin{abstract}
A paisagem não se cria de uma só vez, mas por acréscimos, substituições; a lógica pela qual se fez um objeto no passado era a lógica da produção daquele momento. Uma paisagem é uma escrita sobre a outra, é um conjunto de objetos que têm idades diferentes, é uma herança de muitos diferentes momentos. (...) Assim, a paisagem é uma herança de muitos momentos, já passados, o que levou Lênin a dizer que a grande cidade é uma herança do capitalismo e veio para ficar, devendo os planejadores do futuro levar em conta essa realidade (SANTOS, 2008, p. 73).
\end{abstract}

$\mathrm{Na}$ paisagem "novas" e "velhas" formas podem compor uma mesma realidade harmonizando-se ou gerando novos conflitos, entretanto, observa-se que o novo tende a sobrepor-se, ou, apagar o velho, modificando-a sutilmente ou abruptamente a depender do interesse da lógica do capital, do mercado, no bojo do capitalismo, resultando num novo rearranjo territorial, gerando novas relações socioespaciais na sociedade.

\title{
Praça
}

Os espaços públicos urbanos, (seja as ruas, praças, avenidas, passeios, boulevards, largos, jardins, vielas, vias, esplanadas, praias, cais, pontes, rios, margens, canais e parques), está presente nas diversas localidades das pequenas, médias e grandes cidades sendo indispensável para o lazer e o cotidiano das populações.

A origem das praças é mais antiga do que se imagina. As primeiras referências que se tem conhecimento são a ágora na Grécia Antiga, berço da civilização ocidental, consideradas 
a "[...]verdadeira praça pública, centro da vida urbana. Era o lugar de encontro social, comercial, intelectual, ou artístico. Um autêntico centro cívico onde conclui a dinâmica urbana" (ALVES, 2003, p. 77, apud, FURTADO, 2008, p. 33).

Paralelo a isso, surgiu o fórum, na Roma Antiga, que expressava o símbolo do Imério Romano; “[...] era monumental, misturava edifícios e diversas funcionalidades; uma grande praça descoberta, utilizada para grandes reuniões, comércio, congregações religiosas e assembléias, privada de acesso" (RIBEIRO, 2008, p. 30, apud, FURTADO, 2008, p. 33).

Ao longo do tempo, a praça sofreu alguns desdobramentos na Idade Média sendo ela dividida em praça de mercado e praça da igreja. A do mercado "[...] aberto ao público, lugar de trocas comerciais e de reunião social. A da igreja agregava o Castelo e outros edifícios solenes” (LAMAS, 1993; RIBEIRO, 2008; ALVES, 2003, apud, RIBEIRO, 2008, p. 33).

No Renascimento, as praças ganharam novas dimensões com a implementação da atividade urbanistica, por meio de valores socias, políticos, estéticos e artísitcos na sua funcionalidade (RIBEIRO, 2008, p. 33-34).

No Brasil, os problemas registrados nos grandes centros, a exemplo da concentração e inchaço demográfico, onde mais da metade da população vive nas cidades; as habitações subhumanas e precárias (favelas) as condições precárias dos transportes públicos, a violência urbana, as condições geoclimáticas e ambientais, desafiam o sentido e a existência das praças.

Apesar desse cenário, no Brasil, a praça é palco dos principais eventos históricos que resultaram em marcos e transformações territoriais a exemplo das passeatas contra Regime Didatorial Militar, as Diretas Já, a redemocratização na década de 1980, os processos eleitorais e os movimentos de classe por meio dos trabalhadores, estudantes, dentre outros.

Portanto, concebe-se as praças como

[...] local onde se encontram os amigos, compadres, comadres, crianças, jovens e nem tão jovens assim, em qualquer hora do dia alguém faz uso do espaço. Seja para descançar, passear com a família, praticar alguma atividade, como ler ou jogar dominó com os amigos, brincar, ter contato com a natureza, aliviar as tensões do dia-a-dia ou para simplismente fugir da solidão (DOURADO, 2009, p. 22).

Por fim, eis a percepção que mais se aproxima da proposta deste trabalho observando a realidade que cerca o presente objeto de estudo e suas respectivas propostas metodológicas.

\section{Processos espaciais da/na paisagem urbana da Praça Morena Bela}

A Praça Astrogilda Paiva Guimarães, apelidada pelos moradores de Praça Morena Bela, está localizada no bairro Ginásio, numa área central da cidade de Serrinha e apresenta, 
em sua paisagem, elementos que justificam a realização do presente trabalho a exemplo de escolas e igreja neopentecostal diferente de outras praças que contem, majoritariamente, no seu entorno, o prédio da prefeitura e a matriz da igreja católica.

A localidade da atual Praça Morena Bela era uma grande propriedade rural (Figura 2), porém, se desconhece quem era os proprietários da localidade, visto que, na pesquisa documental, bibliográfica e de arquivos públicos, não se tem registros oficiais que identifiquem a propriedade.

Figura 2 - Antigo portão que dava acesso à localidade do prédio da sericicultura, hoje Colégio Municipal Leobino Cardoso Ribeiro - meados de 1920.

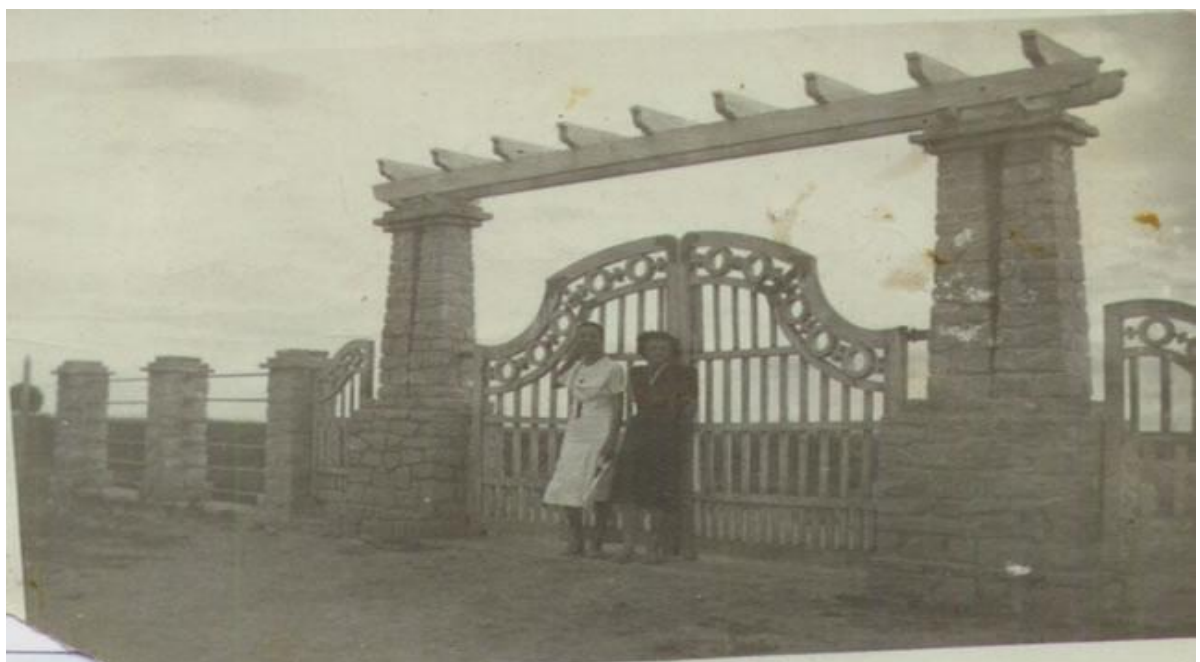

Fonte: Museu Pró Memória de Serrinha, 1920

Décadas posteriores, foi construída no entorno da praça a sede de um projeto agropecuário de sericicultura, mais conhecida como Bicho-da-Seda, FRANCO (2008). A Estação Experimental de Sericicultura de Serrinha foi criada pelo decreto de n. ${ }^{\circ}$ 9.670, no dia 13 de agosto de 1935. Sua construção ocorreu entre os anos de 1935 a 1937, sob a responsabilidade do engenheiro Orlando Teixeira e custou aproximadamente $800.000 \$ 000$ (oitocentos mil contos de réis), sendo concluída no início do ano de 1938. 
Figura 3 - Prédio da antiga Sericicultura em construção, atualmente Colégio Estadual Rubem Nogueira, no ano de 1935

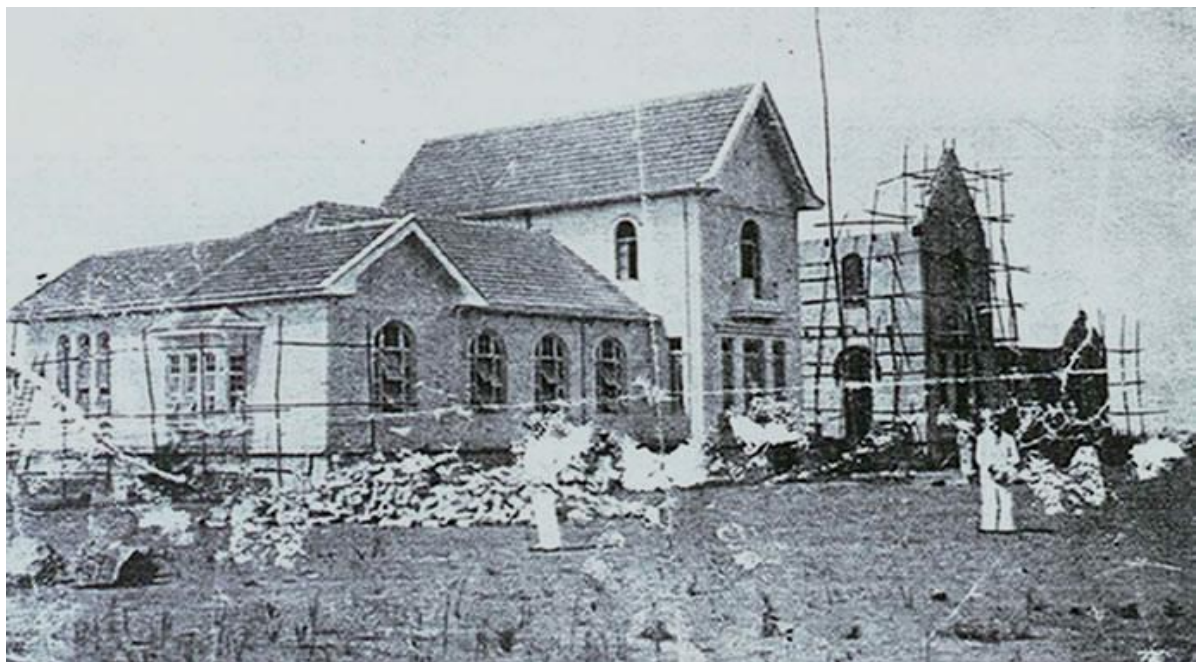

Fonte: Museu Pró Memória de Serrinha, 1935.

Não obstante, percebe-se que o projeto foi mal sucedido e devido a grande seca da década de 1930, “[...] o mesmo foi desativado e o principal prédio foi utilizado para o serviço de estocagem e distribuição de cereais e leguminosas pela mesma secretaria (Figura 4) a fim de amenizar as perdas na lavoura", (PINHEIRO, 1999, p. 13).

Figura 4 - Esboço do projeto "Bicho-da-Seda" desenvolvido pela sericicultura na cidade de Serrinha - 1935



Fonte: Museu Pró Memória de Serrinha, 1935

No ano de 1948, o então deputado estadual e serrinhense Rubem Ribeiro Nogueira, apresentou o projeto de lei para implantação do ginásio público em Serrinha (na antiga Estação Experimental de Sericicultura - Figura 5) e outras cidades, sendo equivalente ao ensino secundário, visto que, somente a capital Salvador dispunha na época do Ginásio da 
Bahia. O referido projeto foi "[...] convertido na Lei n. ${ }^{\circ} 130$ de 14/12/1948 e posteriormente implantada em 25/03/1952, após forte resistência de grupos contrários a iniciativa" (NOGUEIRA, 1997, p. 269).

Figura 5 - Ginásio Regional do Nordeste após a inauguração, hoje Colégio Estadual Rubem Nogueira em Serrinha - 1960

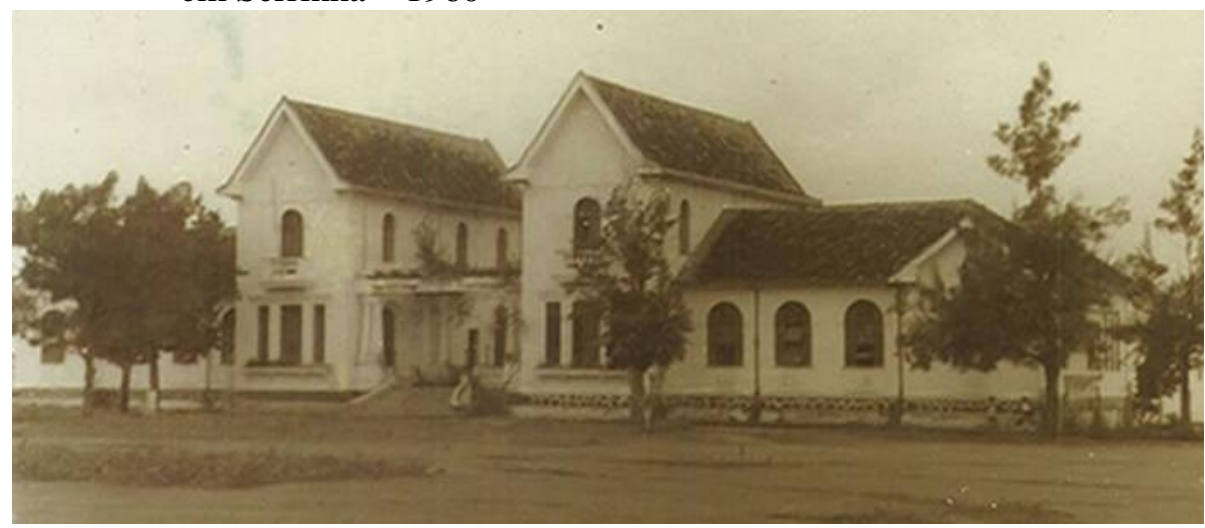

Fonte: Museu Pró Memória de Serrinha, 1960.

Após a implantação do Ginásio Regional do Nordeste, hoje Colégio Estadual Rubem Nogueira, vários equipamentos instalaram-se no seu entorno a exemplo de residências e lojas comerciais. Décadas posteriores, em 1980, a localidade foi pavimentada, criou-se a Biblioteca Municipal, implantou-se a Faculdade de Educação de Serrinha (FES), hoje Departamento de Educação da Universidade do Estado da Bahia (UNEB), Campus XI - Serrinha e o Núcleo Regional de Saúde, antiga 12a Diretoria Regional de Saúde.

Mesmo com o aumento da especulação imobiliária decorrente dos fatos citados acima, defronte ao Colégio Estadual Rubem Nogueira (Figura 6), que resultou na criação do bairro Ginásio devido a escola, persistiu a existência do chamado "selão", um largo de terra com textura avermelhada que servia para atividade esportiva, festividades dos estudantes das escolas instaladas no entorno, dentre outras.

Figura 6 - Colégio Estadual Rubem Nogueira na década de 1980, antes da construção da Praça Morena Bela na cidade de Serrinha

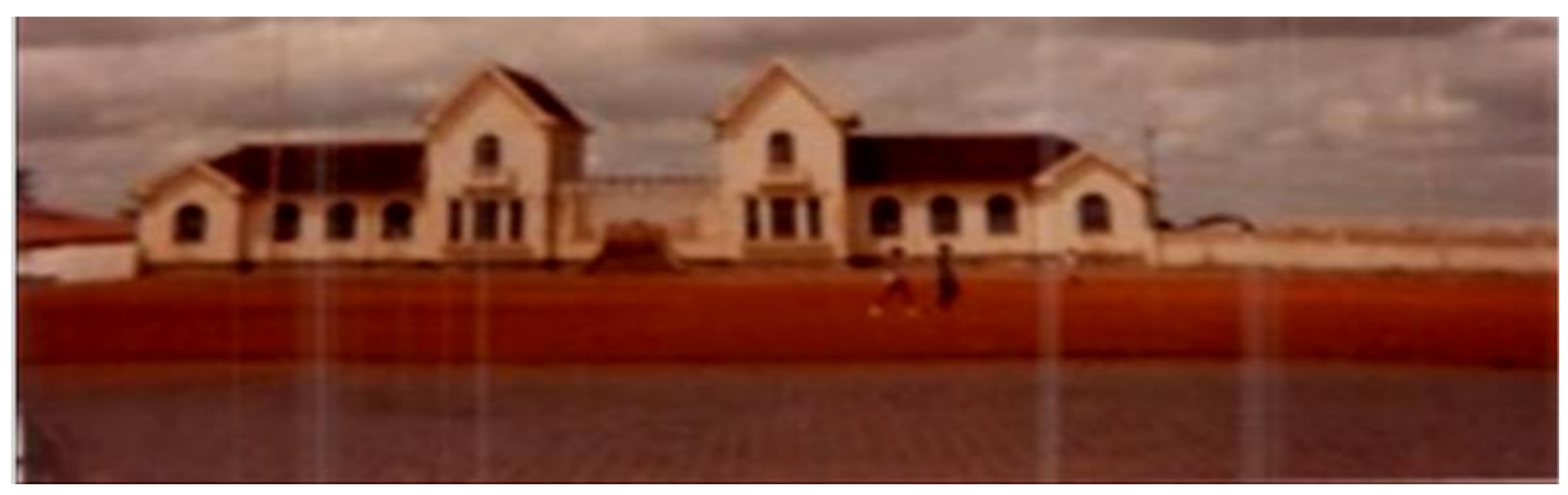

Fonte: Museu Pró Memória de Serrinha, 1980. 
A principal transformação veio com a construção da Praça Astrogilda Paiva Guimarães, em homenagem a professora mais conhecida do antigo Ginásio Regional do Nordeste, ligada ao movimento integralista e ao grupo político do Deputado Rubem Nogueira.

A praça foi inaugurada em 04/11/1988, no aniversário do então prefeito Antônio Josevaldo da Silva Lima. Tratava-se de um marketing eleitoral para eleger o seu sucessor, Paulino Alexandre Santana (Popó) e mostrar sua influência política ao futuro sucesso que foi eleito graças ao uso do público alienado ao privado.

O apelido da praça de Morena Bela (Figura 7), é uma homenagem por parte dos arquitetos e planejadores às morenas de Serrinha como “[...] as mais belas e bonitas de toda a região" (PINHEIRO, 1999, p.16). Ela foi prontamente eleita pela juventude como o mais requisitado espaço de lazer, encontros e entreterimento da cidade em detrimento da Praça Luiz Nogueira e outras.

Figura 7 - Escultura de autoria do artista serrinhense Maninho Pintor em homenagem as mulheres de Serrinha como as mais belas da região - 2007

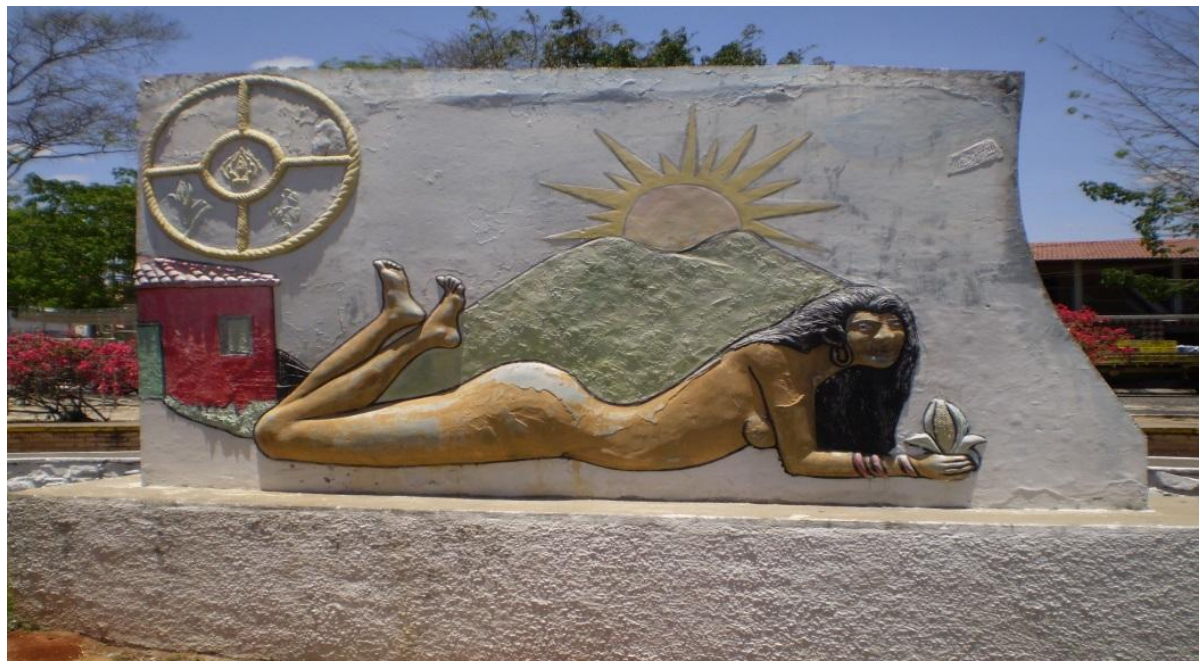

Fonte: Acervo do Autor, 2007.

A praça se diferencia e se destaca no contexto urbano local pelas suas peculiaridades, não possui templos católicos, sede da prefeitura, do mesmo modo, fóruns, bancos, residências da elite política. Tem-se ainda a presença da "barriguda" (Cieba speciosa Ravenna), árvore de grande porte pertencente à família das Malvaceae (antiga Bombacaceae) permitindo um excelente sombreamento. "É conhecida também como paineira e paineira-rosa e é originária do bioma da Mata Atlântica (floresta estacional semidecidual) e Cerrado" (MATOS e QUEIROZ, 2009, p. 101). 
Figura 8 - Praça Morena Bela na cidade de Serrinha - 2010



Fonte: Acervo do Autor, 2010

Tal observação impacta na referida paisagem porque a maioria considerável dos agentes que a frequentam, usam e se apropriam desse espaço são constituídas por adolescentes, jovens e pessoas em idade economicamente ativa. Por isso a praça é uma das localidades mais requisitadas nas festividades, no lazer coletivo e demais sociabilidades.

$\mathrm{Na}$ pesquisa feita por Nunes (2010) os agentes sociais entrevistados, em sua maioria, consideram a praça aconchegante, moderna e bonita, porém, reivindicam junto ao poder público local melhorias pontuais a exemplo da iluminação e pontuais benfeitorias nos equipamentos da praça (jardim infantil, bancos e aparelhos de atividade física) devido a falta de condições de higiene e limpeza.

Desses agentes (servidores públicos, estudantes, transeuntes, comerciantes e moradores), $58 \%$ elegeram o lazer e o entretenimento a principal funcionalidade da Praça Morena Bela por causa dos eventos promovidos pelos bares e restaurantes no entorno; seguida da cultural por $18 \%$ por estar presente no cotidiano de muitos serrinhenses. Em terceiro lugar a econômica com $18 \%$ enquanto principal fonte de renda de comerciantes, vendedores e outros e por fim, com $4 \%$ a política pois as maiores zonas eleitorais estão concentradas nas escolas públicas instaladas no entorno com (4\%).

Na pergunta dirigida aos entrevistados sobre a definição de paisagem, mais da metada consideram-na como "[...] tudo aquilo que está ao alcance dos nossos olhos, algo estático, uma fotografia, tudo que vemos ao nosso redor", seguida daqueles que a definem como "Imagem composta pelos elementos presentes no espaço", segundo (NUNES, 2010, p. 66). 
Dessa forma, a releitura da interpretação de dados, por meio da pesquisa de campo, permite-nos constatar a atualidade das questões apresentadas elucidando de maneira coesa a percepção sobre a paisagem da Praça Morena Bela.

\section{Considerações finais}

Em face da finalização de elaboração do presente texto acerca da temática proposta, apresentamos neste item algumas considerações gerais acerca do trabalho, não objetivando esgotar a temática, mas deste modo, provocar um debate acadêmico acerca do mesmo.

A paisagem da Praça Astrogilda Paiva Guimarães (Morena Bela) de Serrinha, apresenta um conjunto de objetos e elementos que a nossa visão alcança num dado horizonte. Ela é composta de equipamentos, fruto da técnica, elementos naturais por meio da vegetação que se destaca na paisagem e humanos - agentes sociais que usam e se apropriam de um espaço que é público e de uso coletivo.

Sendo a paisagem da praça heterogênea em cores e sensações; dinâmica por ser composta de formas naturais e artificiais, imbricadas de inúmeras temporalidades e funções, constata-se que ela é resultante de inúmeros eventos e modificações.

Desse modo, pode-se afirmar que, nos próximos anos, décadas e séculos a praça não é e nem será estática em sua forma e estrutura pois está sujeita aos processos espaços-temporais da ação humana de acréscimos, substituições na sua paisagem, visto que, o "velho" e o "novo" se relacionam e se complementam.

Entretanto, para os agentes sociais, a praça reflete o sentido do que seja o público de fato, pois, é mantida e gerida pelo poder público que deve zelar por esta condição aproximando-se do que foi à ágora grega, o fórum romano.

Deseja-se que ela seja o palco das inúmeras subjetividades e funcionalidades onde se possa encontrar os pares e casais, passeios familiares e coletivos, contemplar dos elementos que remete a natureza e proporcione o bem estar individual e comunitário

Por fim, sendo a praça algo essencial a prática urbana das cidades, não se pode perder de vista, prioritariamente, a percepção de um lugar privilegiado das manifestações, do exercício pleno, democrático e participativo da cidadania, das reivindicações por melhores condições de vida diminuindo as desigualdades socioespaciais. Esta é apenas uma forma de leitura crítica da paisagem urbana acerca da Praça Morena Bela na cidade de Serrinha. 


\section{Referências}

DOURADO, Lilian Aparecida Campos. A territorialidade na cidade e na praça: Em foco, a estância turística Ilha Solteira - SP. Geointeração, Três Lagoas: V. 1, n. ${ }^{\text {o }}$ 1, p. 20 - 38, 2009.

FRANCO, Tarsso. Serrinha: A colonização portuguesa numa cidade do sertão da Bahia (A história do município de Serrinha). 2 ed. Salvador: EGBA / Assembléia Legislativa do Estado. 2008.

FURTADO, Emanuel António Rodrigues. O papel do espaço público na estruturação do tecido urbano: o caso de Tira Chapéu - Cidade da Praia. Monografia (Bacharelado em Arquitetura). Campus Universitário Cidade da Praia, Universidade Jean Piaget de Cabo Verde. 2008. Disponível em: <http://bdigital.cv.unipiaget.org:8080/jspui/handle/10964/133> Acesso em: 18 ago. 2016.

MACHADO, Robinson. Cobrir para ver. Revista discutindo geografia. São Paulo: Igor Ribeiro, 2008. 4 ed. N. ${ }^{\circ} 20$.

MATOS, Eloina; QUEIROZ, Luciano Paganucci de. Árvores para cidades. Salvador: Ministério Público do Estado da Bahia: Solisluna, 2009. 338 p.

NOGUEIRA, Rubem. O Homem e o Muro (Memórias políticas e outras). São Paulo: Gumercindo Rocha Dorea (edições GRD). 1997. 415 p.

NUNES, Fernando de Souza. O espaço público na dinâmica da paisagem da Praça Morena Bela da cidade de Serrinha-BA. 86 p. Monografia (Licenciatura em Geografia) Departamento de Educação Campus XI - Serrinha, Universidade do Estado da Bahia UNEB. Serrinha: 2010.

PINHEIRO, Denyse Maria Nascimento. A praça é do povo como o céu é do condor: violações ao direito à saúde na Praça Morena Bela Serrinha-BA. P. 58. Monografia (Especialização em Direito Sanitário) - Departamento de Saúde, Universidade Estadual de Feira de Santana UEFS. Feira de Santana: 1999.

SANTOS, Milton. Metamorfose do espaço habitado: fundamentos teóricos e metodológicos da Geografia. 6 ed. São Paulo: EDUSP, 2008.

SCHIER, Raul Alfredo. Trajetórias do conceito de paisagem na Geografia.

Raega, Curitiba, V. 7, 2003, p. 79-85. Disponível em: Http://ojs.c3sl.ufpr.br/ojs2/index.php/raega/article/viewfile/3353/2689 Acesso em: 21 mai. 2018 
A Praça Morena Bela na cidade de Serrinha-BA: uma reflexão a partir da paisagem urbana

Recebido em: 17/01/2018

Aceito para publicação em: 30/04/2018 